\title{
EXAGGERATING AND RETRAINING FACTORS LEADING TO MIGRAINE INCIDENCE IN PAKISTAN
}

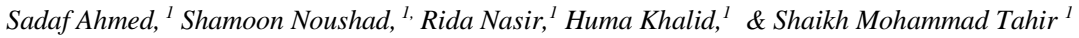 \\ 1. Psychophysiology Research Division, Advance Educational Institute \& Research Centre \\ 2. Neurovascular Physiology \& Biophysics Unit, Department of Physiology, University of Karachi \\ Corresponding author: sadaf@aeirc-edu.com
}

\begin{abstract}
Migraine is a neurological disorder with primary episodes of headache pain affecting populations worldwide. Almost people of all ages and family history are able to develop this pattern of throbbing and unilateral pain with visual disturbance to physical sensations. The key triggers that are most likely to initiate this headache includes psychosocial, economical, environmental or physical stress, hormonal disturbances, dietary variations, high sensitivity to light, smell and sounds.185 subjects both male and females of different ages from 16-60 years were interviewed to investigate the key triggering reasons for migraine attacks. Meanwhile they were also inquired by any restraining factors that help them to get instant or long-lasting relief. Evaluation was done on the basis of ICHD-II criteria. Moreover the family history, socio-economic status and demographic data were also noted. Our results gave a clear view that emotional and mental stress was the key trigger that can exaggerate the feeling of headache with physical strain as the other main burden. Secondly exposure to immense sunlight and bright lights was frequently reported. Other minor initiators observed were lack of sleep, dietary changes, skipped meals, menstruation, and particular smells like fragrance or unpleasant odors. While excessive sleep and medications were noted as chief controls this can restrain headache pain incidence. In this study, emotional stresses were significant in female. Psychological stress is reported to be a major contributor to headaches. The attacks may be relief by proper medication and sleep. Stress and sunlight trigger migraine head pain in majority that can be cure by proper medicine and sleep. KEYWORDS Migraine, triggers, exaggerating, stress, headache
\end{abstract}

\section{INTRODUCTION:}

Migraine is the primary episodes of headache/neurological pain. It is followed by unilateral pain and throbbing and in many cases it may be severe. It can occur in the normal functioning brain, causing it to act abnormally (Goadsby, 2002; May, 1999; Ayata, 2006). Recent studies throughout the world (Africa, Asia, Australia, Europe, North America, Central and South America) showed an average rate prevalence of migraine while western world showed higher than the Japanese population. 4 According to world health organization's estimation, 303 million people suffered migraines worldwide and every day at least 20 million attacks of migraine happen (WHO, 2006). Headache is ranked at fifth position in most disabling condition for women globally (Samaan, 2010). Rate of migraine is more prevalent in females than in males (Goadsby, 2002; Hauser, 2012 \& Martelletti, 2005). In adulthood, the likelihood of women suffering from migraine is three times more than men. In childhood, boys are affected more than girls, but after adolescence, when estrogen influence begins in young girls, the risk of migraine and its severity rises in females. Some scientist have suggested that gonadal steroid may be the reason for headache or migraine as changes occur in estrogen levels at menarche, menstrual period, pregnancy, and menopause (Goadsby, 2002; Dzugan, 2004). Female sex hormones can control majority mediators and receptor systems; these actions may be preserving at the central nervous system and peripheral, neurovascular level. For illustration, women sex hormone have been revealed to enhance: (i) neuronal excitability by increased $\mathrm{Ca} 2+$ and decreasing $\mathrm{Mg} 2+$ concentrations, an action that may occur with other mechanisms triggering migraine; Researchers have demonstrated that increase in estrogen leads a decrease in ionized magnesium but when progesterone levels rise, ionized magnesium levels also rise.

(ii) The synthesis and release of nitric oxide (NO) and neuropeptides, such as calcitonin gene-related peptide CGRP, a mechanism that reinforces vasodilatation and activates trigeminal sensory afferents with stimulation of pain centers. (iii) The function of receptors mediating vasodilatation, while the responses of receptors inducing vasoconstriction are weakened (Gupta, 2007 \& Dzugan, 2006).

The migraine attacks may start at any age; the effect increases more in early to mid-adolescence (Goadsby, 2002). Unfortunately it is also very common in children although there are various theories as to the potential cause(s) of migraine, one of them is the genetic factors (Lin, 2005; Anjum, 2012; Haan, 1997). Diverse numbers of factors were reported that can initiate headache in particular individuals while they are not universal as they vary from person to person. The major triggering factors include food, missed meals, alcohol, menstrual periods, environmental condition, stress and hormonal factors (WHO, 2006; Zagami, 2006; Sauro, 2009 ;Bokhari,2009 \& Sauro, 2009). Psychological and emotional stressors include moods like depression, anger; anxiety, reported a common initiative factor in migraine patients (Anjum, 2012). The aim of this study was to evaluate the most common factors in our population that trigger migraine we also targeted the factors that can contribute to the cure and reduction of migraine in our people.

\section{METHOD:}

185 subjects, including both male and females, ages ranging between 16-60 years were interviewed in order to investigate the major triggering factors that stimulates migraine attacks and restraining factors that help them to get rid of headache and provide long-lasting relief. The inclusion and exclusion criteria was based on sensation of pain in the head, people who reported the pain sensation were studied on the basis of the intensity of pain and other factors like duration, causes, feeling, impact, side of head where pain feels the most, family history etc. socio-economic status and demographic data were also collected. The data was collected before and during examination while evaluation was done on the basis of ICHD-II criteria. 
RESULTS:

\begin{tabular}{|c|c|}
\hline INITIATING FACTORS & $\begin{array}{l}\text { PERCENTAGE OF } \\
\text { RESPONDENTS }\end{array}$ \\
\hline Morning & 7.56 \\
\hline Evening & 37.30 \\
\hline Afternoon & 15.13 \\
\hline During Sleep & 14.59 \\
\hline Beginning of week & 4.32 \\
\hline Middle of week & 8.65 \\
\hline End of week & 8.65 \\
\hline Bright light & 33.51 \\
\hline During or After having sex & 0.54 \\
\hline Period after emotional stress & 37.84 \\
\hline After emotional stress & 23.24 \\
\hline During physical exertion & 10.81 \\
\hline After not eating several hours & 27.57 \\
\hline After napping or over sleep & 17.84 \\
\hline After drinking alcohol & 0.54 \\
\hline Before Menstrual cycle & 7.57 \\
\hline During Menstrual cycle & 5.40 \\
\hline After Menstrual cycle & 1.08 \\
\hline $\begin{array}{l}\text { After bending your head } \\
\text { downwards }\end{array}$ & 17.84 \\
\hline No Pattern & 11.35 \\
\hline
\end{tabular}

Table 1: Most common exaggerating factors for both headache and migraine

\begin{tabular}{lc}
\hline RELIEVING FACTORS & $\begin{array}{l}\text { PERCENTAGE OF } \\
\text { RESPONDENTS }\end{array}$ \\
\hline Sleeping & 38.38 \\
Rest & 28.64 \\
Eating & 14.59 \\
Spinal Adjustment & 2.16 \\
Improving posture & 5.40 \\
\hline Dark quiet room & 29.73 \\
Medication & 36.76 \\
Nothing Helps & 10.27 \\
Drinking coffee & 27.57 \\
Muscle Massage & 12.43 \\
Cold Pack & 3.24 \\
\hline Other & 2.2 \\
\hline
\end{tabular}

Table 2: Most common relieving factors for both headache and migraine.

The most common exaggerating factors were emotional stress, bright light, and period after emotional stress. The most common factors that relieve migraine were: sleeping, medication, dark room, rest and drinking coffee.

\section{DISCUSSION:}

Diverse number of precipitating factors that initiate headache and migraine included in this study were also examined by different authors (WHO, 2006; Anjum, 2012; Sauro, 2009). The current study focused on finding the most common migraine exaggerating factors and relieving factors among headache and migraine sufferers. The major triggers of headache pain in both categories are shown in Table 1, emotional stress, evening time, bright light and hunger are the most common triggers. Stress and bright light are the most common triggers. Studies indicate that stress is the major factor in migraine (Fakhsheena, 2012; Sauro, 2009 \& Bokhari, 2008). Rasmussen and Robbins L et al. reported in their studies that most recurrent factor of migraine and headache was stress and mental tension. Stress/anxiety as activated the central mechanism of the ascending reticular pathway (1994; Spierings, 1997). Here we have seen that evening time was also a major factor that plays a role in initiating migraine. It was mentioned in previous study that finds out the time onset of migraine and indicates a same factor trigger head pain with a low rate (Sauro, 2009). While on another study showed Hassles in the afternoon led to migraine headache that similar to evening or during the night. (Friedman,2009 \& Soleimanpour, 2012). Martins and Prarreira identified six exercises tried by the people, most commonly the migraineurs to improve the head pain during and attack. It is a common observation, by clinicians involved in the headache field that many patients use some natural exercises, of their own that improve their pain. In one of the study that recognize the relieving factors they also observed that sleeping, rest were very useful practice attempt by both groups.

\section{REFERENCES:}

- Al-Shimmery, E.K.(2010) Precipitating and Relieving Factors of Migraine Headache in 200 Iraqi Kurdish Patients. Oman medical journal.25 (3), 212.

- $\quad$ Ayata, C., Jin, H., Kudo, C., Dalkara, T., \& Moskowitz, M. A. (2006). Suppression of cortical spreading depression in migraine prophylaxis. Annals of neurology, 59(4), 652-661.

- Bokhari, F. A., Sami, W., Shakoori, T. A., Ali, S. A., \& Qureshi, G. A. (2008). Clinical characteristics of 226 collegegoing female migraineurs in Lahore, Pakistan--Putting ICHD-2 to the road test. Neuroendocrinology Letters, 29(6), 965.

- Cohan, W. (2013). What Nurses Know... Headaches. Demos Medical Publishing.

- Dzugan, S., \& Armond, S. (2006). LE Magazine.Progesterone Misconceptions.

- Dzugan, S.A. (2004).An innovative new treatment for migraine. Life Extension. 64-73.

- $\quad$ Friedman, D. I., \& De Ver Dye, T. (2009). Migraine and the environment.Headache: The Journal of Head and Face Pain, 49(6), 941-952.

- Goadsby, P. J., Lipton, R. B., \& Ferrari, M. D. (2002). Migraine - current understanding and treatment. N Engl $\mathrm{j}$ Med, 346(4), 257-270.

- Gupta, S., Mehrotra, S., Villalón, C. M., Perusquía, M., Saxena, P. R., \& MaassenVanDenBrink, A. (2007). Potential role of female sex hormones in the pathophysiology of migraine. Pharmacology \& therapeutics, 113(2), 321-340.

- Haan, J., Terwindt, G. M., \& Ferrari, M. D. (1997). Genetics of migraine.Neurologic clinics, 15(1), 43-60.

- Haque, B., Rahman, K. M., Hoque, A., Hasan, A. H., Chowdhury, R. N., Khan, S. U., ... \& Mohammad, Q. D. (2012). Precipitating and relieving factors of migraine versus tension type headache. BMC neurology, 12(1), 82.

- Hauser, L. (2012). Migraines and Perimenopause. Nursing for women's health, 16(3), 247-250. 
- $\quad$ Lin, J., P. Wang, C. Chen, K. Yueh, S. Lin, H. Harn.(2005). Homozygous deletion genotype of angiotensin converting enzyme confers protection against migraine in man. Acta Neurologica Taiwanica.14(3), 120.

- $\quad$ Martelletti, P., Haimanot, R. T., Láinez, M. J., Rapoport, A. M., Ravishankar, K., Sakai, F., ... \& Steiner, T. J. (2005). The global campaign (GC) to reduce the burden of headache worldwide. The International Team for Specialist Education (ITSE). The journal of headache and pain, 6(4), 261-263.

- May, A., Ashburner, J., Büchel, C., McGonigle, D. J., Friston, K. J., Frackowiak, R. S. J., \& Goadsby, P. J. (1999). Correlation between structural and functional changes in brain in an idiopathic headache syndrome. Nature medicine, 5(7), 836-838.

- $\quad$ Samaan, Z., MacGregor, E. A., Andrew, D., McGuffin, P., \& Farmer, A. (2010). Diagnosing migraine in research and clinical settings: The validation of the Structured Migraine Interview (SMI). BMC neurology, 10(1), 7.

- Sauro, K. M., \& Becker, W. J. (2009). The stress and migraine interaction.Headache: The Journal of Head and Face Pain, 49(9), 1378-1386.

- Sauro, K. M., \& Becker, W. J. (2009). The stress and migraine interaction.Headache: The Journal of Head and Face Pain, 49(9), 1378-1386.

- Selby, George, James W. Lance.(1960) Observations on 500 cases of migraine and allied vascular headache.Journal of neurology, neurosurgery, and psychiatry. 23(1), 23.

- Singh, S., Harsh, N. S. K., \& Gupta, P. K. A NOVEL METHOD OF ECONOMICAL CULTIVATION OF MEDICINALLY IMPORTANT MUSHROOM, GANODERMA LUCIDUM.

- $\quad$ Spierings, E. L., Sorbi, M., Maassen, G. H., \& Honkoop, P. C. (1997). Psychophysical precedents of migraine in relation to the time of onset of the headache: the migraine time line. Headache: The Journal of Head and Face Pain, 37(4), 217220.

- World Health Organization.(2006). "Headache disorders. Fact Sheet No. 277. March 2004." Retrieved from http://www.who.int/mediacentre/factsheets/fs277/en/

- Zagami, A. S., \& Bahra, A. (2006). Symptomatology of migraines without aura.The Headaches, 3rd edn. Lippincott Williams \& Wilkins, Philadelphia, 399-405. 